\title{
KAJIAN BIO-TEKNIK PEMANFAATAN SUMBERDAYA IKAN TENGGIRI DAN DISTRIBUSI PEMASARANNYA DI KABUPATEN BANGKA
}

\section{(STUDY ON BIO-ENGINEERING TENGGIRI RESOURCES AND MARKETING DISTRIBUTION IN BANGKA DISTRICT)}

\author{
Moch. Prihatna Sobari ${ }^{1}$ dan Arief Febrianto ${ }^{2}$
}

\begin{abstract}
This study aims to identify up to, local, seasonal fishing, fishing equipment productivity tenggiri, marketing of the catch and determine patterns of utilization of resources yellow tail fish in a sustainable Kabupaten Bangka. Research method used was the descriptive survey method of case study (case study) and the sampling is done purposively. Data analysis includes the analysis and bioengineering techniques. Analysis of bio-engineering approach using model CYP. Tenggiri fish in the waters of Bangka Regency arrested with using gillnet catch and pacing overextend. Gill nets in Kabupaten Bangka included in jaringi gill away (drift gillnet) and his fishing nets with the net tenggiri term. Kontruksi catching equipment consists of selambar ropes, nets, rope and buoy up ris. Overextend rod for fishing tenggiri have construction that consists of the Reel (rooler), swivel (swivel), string (line), ballast (sinker) and the rod (book). Fishing season in the month at The Bangka-month fishing season which occurs on the March, May and June and August and October with the IMP more than 100\%. Regional utilization of fishing ground catching fish tenggiri at The Regency Bangkea is catching on line 1 (in the coastal waters of up to 6 miles). Utilization of fish resources in sustainable tenggiri can be done with the regime to know the management of fish resources optimally tenggiri where the alleged biological biological overfishing has occurred with the actual effort is 798 more than the trip management of fish resources optimally tenggiri trip of 379. Tenggiri local marketing of fish is done by traders and merchants and retailers sold to consumers, while the export is done by marketing companies. Selling price, marketing margins and profits earned with the short channel with Fisherman share the same akan provide for share traders and the larger fishing companies.
\end{abstract}

Keywords : bio-engineering study, gillnet, rod overextend, fish resources and aquatic tenggiri Bangka Regency

\begin{abstract}
ABSTRAK
Penelitian ini bertujuan untuk mengindentifikasi bangun, daerah, musim penangkapan ikan, produktivitas alat penangkapan ikan tenggiri, pemasaran hasil tangkapan serta menentukan pola pemanfaatan sumberdaya ikan ekor kuning yang berkelanjutan di Kabupaten Bangka. Metode penelitian yang digunakan adalah metode deskriptif survei yang bersifat studi kasus (case study) dan pengambilan sampel dilakukan secara purposive. Analisis data yang dilakukan mencakup analisis teknik dan bio-teknik. Analisis bio-teknik menggunakan pendekatan model CYP. Ikan tenggiri di perairan Kabupaten Bangka ditangkap dengan menggunakan alat tangkap gillnet dan pacing ulur. Jaring insang di Kabupaten Bangka termasuk dalam jaringi insang hanyut (drift gillnet) dan nelayan menyebut jaring ini dengan istilah jaring tenggiri. Kontruksi alat tangkap ini terdiri atas tali selambar, jaring, pelampung dan tali ris atas. Pancing ulur untuk penangkapan ikan tenggiri memiliki konstruksi yang terdiri atas reel (rooler), kili-kili (swivel), senar (line), pemberat (sinker) dan mata pancing (hook). Musim penangkapan ikan yang ada di Perairan Bangka pada bulan-bulan dimana terjadi musim ikan yaitu pada Bulan Maret, Mei dan Juni serta Agustus dan Oktober dengan IMP lebih dari 100\%. Daerah penangkapan pemanfaatan fishing ground ikan tenggiri di Perairan Kabupaten Bangka yaitu pada jalur penangkapan 1 (pada perairan dari pantai sampai 6 mil). Pemanfaatan sumberdaya ikan tenggiri secara sustainable dapat dilakukan dengan mengetahui rejim pengelolaan sumberdaya ikan tenggiri secara optimal dimana secara biologi diduga telah terjadi biological overfishing dengan effort aktual sebesar 798 trip lebih besar dari pengelolaan sumberdaya ikan tenggiri secara optimal sebesar 379 trip. Pemasaran lokal ikan tenggiri dilakukan oleh pedagang pengumpul dan pedagang pengecer dan selanjutnya dijual ke konsumen, sedangkan pemasaran ekspor dilakukan oleh perusahaan. Harga jual, margin pemasaran dan keuntungan yang diperoleh dengan saluran makin pendek dengan fisherman share yang sama akan memberikan share bagi pedagang dan perusahaan perikanan lebih besar.
\end{abstract}

Kata kunci : Kajian bio-teknik, gillnet, pancing ulur, sumberdaya ikan tenggiri dan perairan Kabupaten Bangka

\footnotetext{
${ }^{1}$ Staff Pengajar di Bagian Teknologi Alat Penangkapan Ikan, Dep. PSP FPIK-IPB

${ }^{2}$ Staff di Dinas Perikanan dan Kelautan Provinsi Bangka-Belitung
} 


\section{PENDAHULUAN}

Kabupaten Bangka merupakan salah satu sentra atau pusat kegiatan sektor perikanan tangkap di Provinsi Kepulauan Bangka Belitung dengan tingkat produksi sebesar 19.661,25 ton. Kekayaan sumberdaya pesisir dan kelautan yang cukup melimpah, yaitu sebesar $23.906,25$ ton per tahun membuat banyak penduduk yang bermata pencaharian sebagai nelayan tetap, disamping nelayan yang mempunyai mata pencaharian sampingan seperti berkebun dan beternak (Dinas Perikanan dan Kelautan Kabupaten Bangka 2006).

Hasil tangkapan yang didaratkan di Kabupaten Bangka pada tahun 2005 mencapai 19.641,60 ton. Hasil tangkapan dominan yang diperoleh nelayan adalah ikan tembang (Sardinella sp) sebesar 17,6\%, ikan tenggiri (Scomberomorus commerson) sebesar 6,2 \% dan ikan kembung (Rastrelliger $\mathrm{sp}$ ) sebesar 9,7\%.

Ikan tenggiri merupakan ikan bernilai ekonomis tinggi yang ditangkap dengan menggunakan alat tangkap gillnet dan pancing ulur. Ikan tenggiri merupakan komoditas unggulan perikanan di Kabupaten Bangka. Di masa mendatang diperkirakan permintaan komoditas ini baik dalam bentuk segar maupun olahan akan terus mengalami peningkatan. Indikator yang menunjukkan hal tersebut adalah semakin banyaknya diversifikasi produk olahan ikan seperti empek-empek, krupuk, kemplang dan abon berbahan baku ikan tenggiri. Hal ini tentunya akan mengakibatkan semakin meningkatnya tekanan penangkapan terhadap sumberdaya ikan tengiri. Meningkatnya eksploitasi sumberdaya ikan sebagai akibat meningkatnya permintaan terhadap sumberdaya tersebut sudah barang tentu berdampak pada semakin tingginya tekanan terhadap keberadaan sumberdaya ikan di Kabupaten Bangka.

Kegiatan perikanan tenggiri di Kabupaten Bangka tidak hanya mencakup masalah sumberdaya ikan dan faktor produksi, tetapi juga masalah distribusi pemasaran hasil tangkapan. Penelitian ini bertujuan untuk mengindentifikasi bangun, daerah dan musim penangkapan dan produktivitas alat tangkap iakan tenggiri, serta menentukan pola pemanfaatan sumberdaya ikan tenggiri yang berkelanjutan.

\section{METODE PENELITIAN}

Penelitian dilaksanakan Agustus sampai dengan Desember. Metode yang digunakan dalam penelitian ini adalah metode deskriptif survei yang bersifat studi kasus (case study). Metode deskriptif survei, yaitu mengumpulkan data sebanyakbanyaknya mengenai faktor-faktor yang mendukung penelitian yaitu potensi penangkapan dan pengembangan usaha perikanan tenggiri di Kabupaten Bangka. Data primer diperoleh langsung di lapangan melalui pengamatan terhadap unit penangkapan ikan ekor kuning dan melakukan wawancara terhadap nelayan berdasarkan kusioner.

Metode pengambilan contoh dilakukan secara purposive. Responden contoh yang diambil adalah nelayan pemilik pedagang pengumpul, pengercer dan perusahaan perkanan yang mewakili sifat-sifat dari keseluruhan responden yang telibat dalam penangkapan ikan tengiri di Kabupaten Bangka, berjumlah 20 nelayan gillnet dan 30 nelayan pancing, serta 14 orang pedagang pengumpul, 18 orang pedagang pengecer dan 2 perusahaan perikanan, 10 orang konsumen. Data sekunder diperoleh dari Dinas Kelautan dan Perikanan Kabupaten Bangka. Data yang diambil data bulanan dan bersifat urut waktu (time series data) dari Tahun 2002 sampai dengan Tahun 2006, meliputi data produksi dan input yang digunakan (effort) dalam pemanfaatan sumberdaya ikan tenggiri.

Analisis data yang dilakukan mencakup analisis teknik, bio-teknik dan distribusi pemasaran. Analisis teknik meliputi kajian terhadap keragaan unit penangkapan muroami. Analisis bio-teknik menggunakan pendekatan model CYP, dan distribusi pemasaran meliputi rantai saluran pemasaran dan margin pemasaran.

\subsection{Aspek teknik}

Analisis teknik dilakukan untuk melihat hubungan faktor-faktor teknik yang mempengaruhi produksi, yaitu konstruksi alat tangkap, produktivitas alat tangkap, daerah dan musim penangkapan. Produktivitas dihitung untuk mengetahui produktivitas per alat, produktivitas per trip dan produktivitas per nelayan, produktivitas per biaya operasional dan produktivitas per biaya investasi. 


\subsection{Standarisasi alat tangkap}

Standarisasi upaya yang dilakukan pada penangkapan target species dengan alat tangkap dominan dilakukan dalam rangka estimasi parameter biologi dalam perikanan yang multi species dan multi gear untuk menghindari variasi species (ikan yang tertangkap dalam upaya yang dilakukan selain target species) dan variasi

$$
\text { CPUEs }=\frac{C s t d}{E s t d} ; \text { FPIs }=\frac{C P U E i}{C P U E s},
$$

$$
\text { Estd }=\sum_{i=1}^{n}
$$

gear (alat tangkap yang ada dari alat tangkap sejenis yang tidak beroperasi). Standarisasi effort dilakukan dengan menggunakan unit jumlah trip per bulan selama tahun 2001-2005 dari dua alat tangkap, yaitu pancing dan gillnet yang distandarisasikan ke alat tangkap pancing. Rumus yang digunakan untuk standarisasi adalah sebagai berikut:

Keterangan:

$$
C P U E i=\frac{C i}{E i} ; F P I i=\frac{C P U E i}{C P U E S}
$$

(FPI $\mathrm{x}$ effort ke- $\mathrm{i})$

$C t_{s t d} \quad:$ Hasil tangkapan (catch) alat tangkap standar,

$E_{\text {std }} \quad$ : Upaya penangkapan (effort) alat tangkap standar,

$\mathrm{C}_{\mathrm{i}} \quad$ : Hasil tangkapan tahun ke- $i$ jenis alat tangkap lain,

$E_{i} \quad$ : Upaya tangkap tahun ke-i jenis aiat tangkap lain,

$C P U E_{s}$ : Hasil tangkapan per upaya penangkapan alat tangkap standar;

$C P U E_{i}:$ Hasil tangkapan per upaya penangkapan alat tangkap $i$,

$F P I_{s} \quad$ : Fishing power index alat tangkap standar,

$F P I_{i} \quad$ : Fishing power index alat tangkap lain.

\subsection{Analisis bio-teknik}

Analisis

bio-teknis

didekati

menggunakan metode surplus produksi dari Schaefer MB (1954) diacu dalam (Sobari, Diniah, Widiastuti 2008). Model produksi Schaefer yang menghubungkan antara

$$
h=q k E-\frac{q^{2} k}{r} E^{2}
$$

Pendugaan parameter biologi dilakukan dengan metode surplus produksi

$$
\begin{gathered}
\operatorname{In}\left(U_{t+1}\right)=\frac{2 r}{2+r} \operatorname{In}(q k)+\frac{(2-r)}{(2+r)} \operatorname{In} U-\frac{q}{2+r}\left(E_{t}+E_{t+1}\right) \\
\operatorname{In}\left(U_{t+1}\right)=\alpha+\beta \operatorname{In}\left(U_{t}\right)-\gamma\left(E_{t}+E_{t+1}\right)
\end{gathered}
$$

Nilai-nilai parameter $r, q$ dan $\mathrm{k}$ parameter $r, q$ dan $k$ dapat diperoleh dari diestimasi dengan menggunakan metode persamaan: OLS (Ordinary Least Square), sehinga nilai

$$
r=\frac{2(1-\beta)}{(1+\beta)} q=-\gamma(2+r)
$$

\subsection{Distribusi pemasaran}

Analisis pemasaran difokuskan pada jalur pemasaran komoditas, margin pemasaran. Analisis jalur pemasaran dan harga dilakukan secara deskriptif berdasarkan hasil wawancara dan data perkembangan harga ikan selama 1 (satu) bulan. Perhitungan margin pemasaran diperoleh melalui persamaan berikut:

Keterangan :

$$
M_{i}=H_{i}-H_{i-1}
$$

$M_{i} \quad=$ Margin pada pedagang perantara ke- $i$ ikan tenggiri (Rp per kg)

$H_{i} \quad=$ Harga penjualan pedagang perantara ke- $i$ ikan tenggiri (Rp per kg)

$H_{i-1}=$ Harga pembelian pedagang perantara ke- $i$ ikan tenggiri (Rp per kg) 
Besar keuntungan $(K)$ pada masing-masing lembaga pemasaran dikalkulasi dengan menggunakan persamaan:

$$
\begin{aligned}
\text { Keterangan }: & \\
K & =\text { Keuntungan (Rp per } \mathrm{kg}) \\
M & =\text { Margin (Rp per } \mathrm{kg}) \\
B & =\text { Biaya (Rp per kg) }
\end{aligned}
$$

$$
K=M-B
$$

Rasio keuntungan biaya dihitung dengan menggunakan persamaan :

$$
\text { Rasio keuntungan }- \text { biaya }=\frac{M-B}{B}
$$

Fishermen share dihiting dengan meng-gunakan persamaan :

$$
\text { Fishermen share }=\frac{H j N}{H j K a} x 100 \%
$$

Keterangan :

$$
\begin{array}{ll}
\text { Fishermen share } & =\text { Bagian yang diperoleh nelayan }(\%) \\
H j N & =\text { Harga jual nelayan }(\mathrm{Rp}) \\
\mathrm{Hj} \mathrm{Ka} & =\text { Harga jual pada konsumen }
\end{array}
$$

\section{HASIL DAN PEMBAHASAN}

\subsection{Aspek Teknik}

Ikan tenggiri ditangkap di perairan Kabupaten Bangka menggunakan alat tangkap gillnet dan pancing ulur. Adapun kontruksi kedua alat tangkap tersebut adalah sebagai berikut:

\section{(a) Kontruksi jaring insang (gillnet)}

Gillnet yang digunakan untuk menangkap ikan tenggiri, yaitu jaring insang hanyut (drift gillnet). Nelayan di Kabupaten Bangka menyebut jaring ini dengan istilah jaring tenggiri. Alat tangkap ini terdiri atas tali selambar, jaring, pelampung dan tali ris atas (Gambar 1)

Jaring tenggiri terbuat dari bahan $P A$ warna jaring hijau nomor 80 dan diameter $0,5 \mathrm{~mm}$. Alat tangkap ini berbentuk segi empat dengan tinggi jaring $18-23 \mathrm{~m}$, panjang $1.200-2.200 \mathrm{~m}$ terdiri atas $30-40$ piece dengan ukuran 1 piece mencapai 45$55 \mathrm{~m}$. Ukuran mata jaring yang digunakan, yaitu 2,15-3,5 inci. Badan jaring memiliki tinggi 17,5-19,5 $\mathrm{m}$ dengan ukuran mata jaring 2,15-3,5 inci, sedangkan kaki jaring memiliki ukuran 2-2,75 m dengan ukuran mata jaring 3,5-4 inci.

Tali selambar yang digunakan sebagian besar nelayan Kabupaten Bangka memiliki panjang rata-rata $19 \mathrm{~m}$ yang berfungsi sebagai penghubung antara kapal dengan alat tangkap yang digunakan. Bahan yang digunakan, yaitu $P E$ dengan diameter sama dengan tali ris atas, yaitu 8$10 \mathrm{~mm}$.

Tali ris atas terbuat dari bahan $P E$ yang terbagi dalam 2 tali. Diameter tali yang digunakan, yaitu $10 \mathrm{~mm}$ dan $8 \mathrm{~mm}$. Fungsi tali yang memiliki diameter lebih besar, yaitu sebagai penyatu antara tali ris atas dengan jaring, sedangkan tali yang memiliki ukuran lebih kecil berfungsi sebagai penghubung antara tali ris atas dengan pelampung. Fungsi tali ris atas pada jaring ikan tenggiri ini adalah sebagai penghubung dengan pelampung dan jaring.

Pelampung terbuat dari bola plastik dengan diameter $25 \mathrm{~cm}$ sebanyak 4 buah dalam 1 piece jaring, keempat pelampung ini diikat satu sama lain kemudian diikatkan pada tali ris atas dengan menggunakan tali $P E$ (polyethylene). Jarak antara pelampung satu ke pelampung lainnya, yaitu 10-15 m. Pelampung selain berfungsi untuk mengapungkan badan jaring ke atas permukaan, juga ber fungsi sebagai tanda keberadaan jaring tenggiri selama di perairan.

\section{(b) Kontruksi pancing ulur (hand line)}

Pancing yang digunakan untuk menangkap ikan tenggiri di Kabupaten Bangka tergolong dalam pancing ulur. Pancing ulur untuk penangkapan ikan tenggiri memiliki konstruksi yang terdiri atas reel (rooler), kili-kili (swivel), senar (line), pemberat (sinker) dan mata pancing (hook) (Gambar 2).

Reel yang digunakan berbentuk seperti roda berfungsi sebagai tempat penyimpanan senar agar tidak mudah kusut saat melakukan penarikan alat tangkap. Senar pancing yang digunakan terbuat dari bahan monofilament. Senar pancing terdiri atas dua bagian, yaitu senar utama (main line) dan senar cabang (branch 
line). Senar utama merupakan senar yang digulung pada reel dan berujung pada kilikili pertama. Senar utama terbuat dari bahan nylon monofilament warna putih transparan dan bernomor 300-500 dengan diameter 1 milimeter, sedangkan senar cabang terbuat dari bahan monofilament yang memiliki ukuran 200-300. Panjang senar utama adalah 30-50 $\mathrm{m}$ dan senar cabang $<6 \mathrm{~m}$.
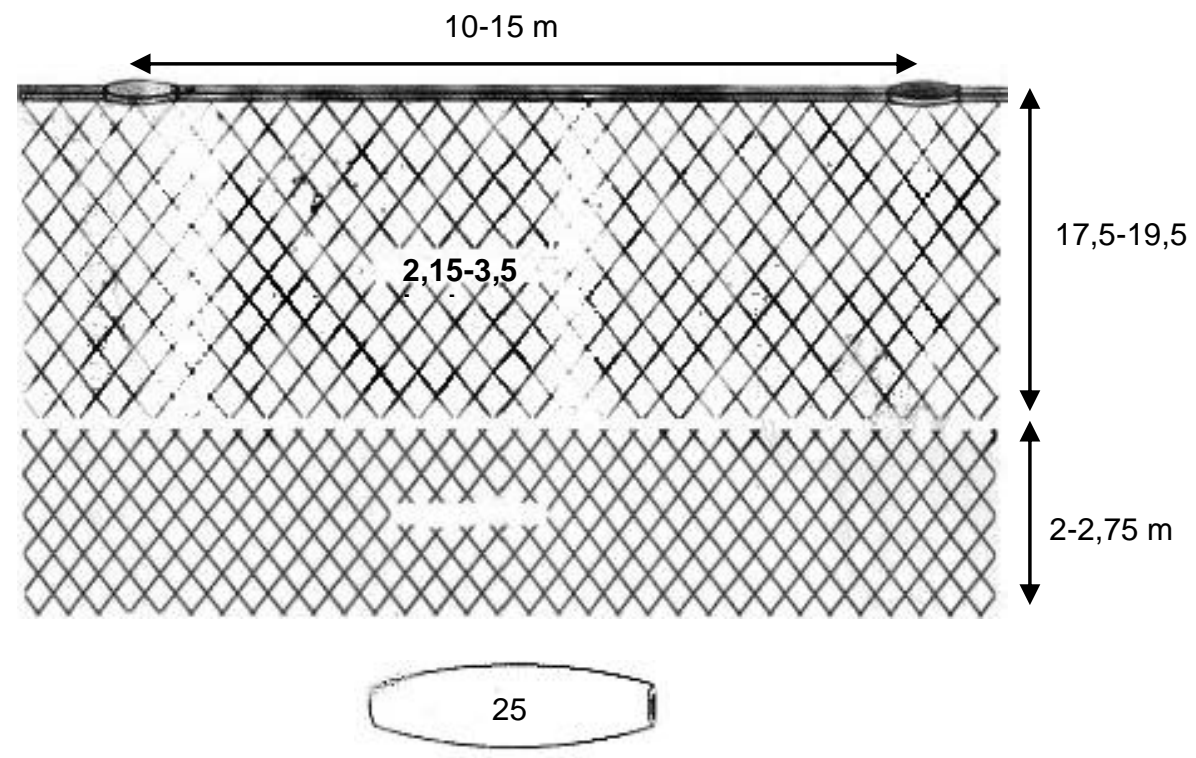

$1200 \mathrm{~m}-2200$ PE Ø 8-10

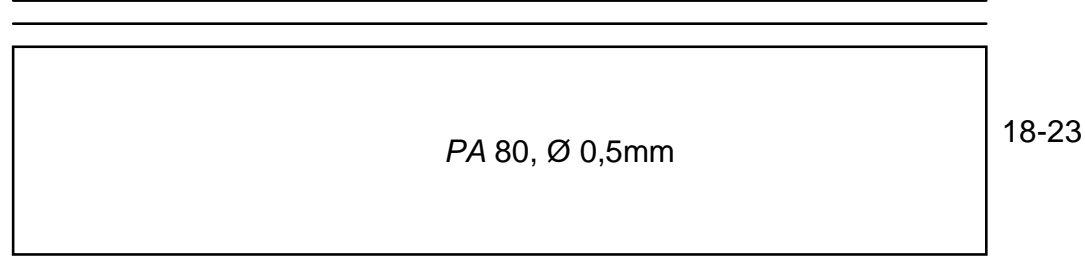

Gambar 1 Konstruksi gillnet di Kabupaten Bangka

Pemberat terbuat dari timah dan ada juga yang terbuat dari besi. Fungsi pemberat adalah untuk memberikan gaya berat pada senar pancing agar dapat tenggelam pada kedalaman yang diinginkan. Kili-kili digunakan agar senar pancing tidak terpelintir dan menjadi kaku, baik karena pengaruh arus maupun karena gerak ikan yang memakan umpan. Kili-kili yang digunakan pancing ulur di Kabupaten Bangka sebagian besar terdapat 2 buah. Kili-kili pertama diikatkan pada ujung senar utama, sedangkan kili-kili kedua diikatkan pada pangkal senar cabang. Kili-kili terbuat dari baja berwarna putih.

Diantara kili-kili pertama dan kedua terdapat kawat barlen yang terbuat dari baja berwarna putih yang panjangnya 50 cm. Fungsinya agar senar cabang tidak membelit pada senar utama sewaktu menurunkan senar pancing ke dalam air ataupun ketika berada di dalam air. Kawat ini diikatkan kepada kili-kili pertama dan kedua dengan menggunakan senar yang sama ukurannya dengan senar utama sepanjang 15-20 cm. Senar ini juga merupakan tempat diikatkannya pemberat.

Pada tiap ujung senar cabang diikatkan sebuh mata pancing (hook). Mata pancing diikatkan pada tali cabang dengan menggunakan kawat rambut yang terbuat dari baja ataupun besi. Panjang kawat barlen yang menghubungkan senar cabang dengan mata pancing antara $10-15 \mathrm{~cm}$.

\subsection{Produktivitas unit penangkapan ikan tenggiri}

Produktivitas yang diukur dalam unit penangkapan ikan tenggiri adalah produksi per trip, produksi per kapal, produksi per nelayan, produksi per biaya operasional, produksi per biaya investasi (Tabel 1). Hasil perhitungan menunjukkan bahwa nilai produktivitas pada gillnet adalah sebesar 1,38 per trip gillnet, 11,40 per kapal dan 30,1 per nelayan per bulan. Produktivitas menurut biaya operasional pada usaha perikanan tenggiri dengan gillnet dan 
pancing, yaitu sebesar $0,03 \mathrm{~kg}$ dan $0,02 \mathrm{~kg}$ per rupiah. Hal ini berarti setiap satu rupiah biaya yang dikeluarkan dapat menghasilkan ikan sebanyak 0,03 kg per rupiah pada gillnet dan $0,02 \mathrm{~kg}$ per rupiah pada pancing ulur. Produktivitas pada usaha perikanan tenggiri dengan gillnet dan pancing ulur menurut biaya investasi, yaitu sebesar 0,01 kg dan 0,01 kg per rupiah. Hal ini berarti bahwa setiap satu rupiah biaya yang ditanamkan dapat menghasilkan ikan sebanyak 0,01 kg dan 0,01 kg.

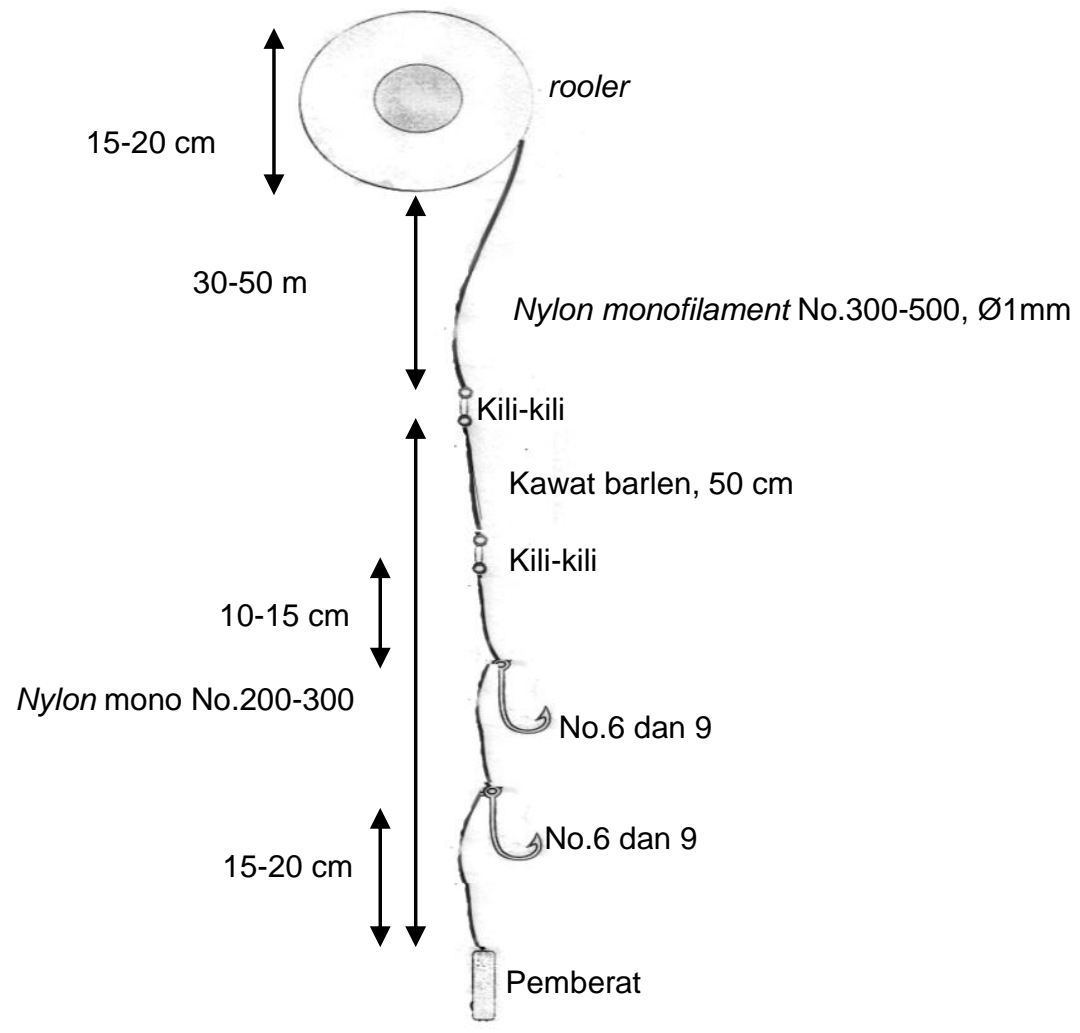

Gambar 2 Konstruksi pancung ulur di Kabupaten

Tabel 1 Produktivitas rata-rata bulanan komponen unit penangkapan ikan tenggiri

\begin{tabular}{|c|l|c|c|}
\hline \multirow{2}{*}{ No. } & \multicolumn{2}{|}{ Komponen unit penangkapan } & \multicolumn{2}{|c|}{ Produktivitas } \\
\cline { 3 - 4 } & & Gillnet & Pancing ulur \\
\hline 1. & Produksi per trip (kg per trip) & 1,38 & 1,93 \\
\hline 2. & Produksi per kapal (kg per kapal) & 11,4 & 4,92 \\
\hline 3. & Produksi per nelayan (kg per orang) & 30,1 & 14,79 \\
\hline 4. & Produksi per biaya operasional (kg per Rp) & 0,03 & 0,02 \\
\hline 5. & Produksi per biaya investasi (kg per Rp) & 0,009 & 0,011 \\
\hline
\end{tabular}

Sumber : Data diolah 2007.

\subsection{Musim penangkapan ikan tenggiri}

Musim penangkapan ikan tenggiri di Kabupaten Bangka dilakukan hampir sepanjang tahun dan cenderung mengalami fluktuasi setiap bulannya dengan kisaran IMP antara 72,75-122.64\%. Musim penangkapan terjadi pada bulan Mei sampai dengan Agustus dengan nilai IMP masingmasing sebesar 122,64\%, 120,33\%, $103,09 \%, 118,15 \%$, serta bulan Oktober dan Maret dengan nilai IMP $110,61 \%$ dan $113,25 \%$. Pola musim penangkapan ikan tenggiri dianalisis dengan metode rata-rata bergerak (moving average) dengan kriteria penentuan musim didasarkan pada besaran indeks musim penangkapan (IMP) Musim penangkapan terendah terjadi pada bulan November dan Desember (Musim Barat) dengan nilai IMP sebesar $76,99 \%$ dan $72,75 \%$ (< rata-rata IMP bulanan). Hasil perhitungan menunjukkan bahwa nilai rata-rata IMP per bulan diketahui sebesar 100\% (Tabel 2). 
Tabel 2 Nilai IMP ikan tenggiri tahun 2001-2005

\begin{tabular}{|c|l|r|c|}
\hline No. & \multicolumn{1}{|c|}{ Bulan } & Nilai IMP $(\%)$ & Musim di Bangka \\
\hline 1. & Juli & 103,09 & Musim Timur \\
\hline 2. & Agustus & 118,15 & Musim Timur \\
\hline 3. & September & 78,66 & Musim Timur \\
\hline 4. & Oktober & 110,61 & Musim Barat \\
\hline 5. & November & 76,99 & Musim Barat \\
\hline 6. & Desember & 72,75 & Musim Barat \\
\hline 7. & Januari & 100,65 & Musim Barat \\
\hline 8. & Februari & 84,81 & Musim Barat \\
\hline 9. & Maret & 113,25 & Musim Barat \\
\hline 10. & April & 98,03 & Musim Timur \\
\hline 11. & Mei & 122,64 & Musim Timur \\
\hline 12. & Juni & 120,33 & Musim Timur \\
\hline
\end{tabular}

Sumber : Hasil analisis 2007

\subsection{Daerah penangkapan ikan tenggiri}

Penentuan daerah penangkapan ikan tenggiri oleh nelayan berpedoman pada indikasi alam. Biasanya nelayan melihat tanda seperti ada tidaknya gemercik air, air berbusa, burung-burung yang terbang dekat permukaan air, dan warna air yang lebih gelap. Selain itu nelayan juga melihat keberadaan karang-karang besar yang biasanya di sekitar karang tersebut banyak terdapat ikan tenggiri.

Daerah penangkapan ikan tenggiri oleh nelayan Belinyu, Merawang, Riau Silip, Sungailiat umumnya berada di sekitar Laut Cina Selatan dan Laut Natuna. Lama perjalanan untuk masing-masing nelayan tidak sama tergantung jauh dan dekatnya daerah tangkapan dari lokasi fishing basenya. Nelayan di Kecamatan Sungailiat melakukan perjalanan menuju lokasi penangkapan biasanya di perairan Kabupaten Bangka selama 5-7 jam perjalanan, sedangkan nelayan Belinyu daerah penangkapannya di Perairan Kabupaten Bangka sebelah Timur dengan lama perjalanan 2-3 jam dan sebelah Utara Pulau Bangka dengan lama perjalanan 4 jam.

Daerah penangkapan ikan tenggiri oleh nelayan di Kecamatan Puding Besar dan Mendo Barat melakukan operasi penangkapan di sekitar Selat Bangka. Lama perjalanan menuju lokasi penangkapan tergantung jauh dekatnya daerah penangkapan, yaitu antara 2-4 jam.

\subsection{Aspek Bio-teknik Sumberdaya Ikan Tenggiri Produksi dan effort}

Di perairan Kabupaten Bangka ikan tenggiri ditangkap dengan menggunakan alat tangkap gillnet dan pancing ulur. Produksi rata-rata bulanan terbanyak, dihasilkan alat tangkap gillnet, yaitu mencapai 10,54 ton per bulan, dan pancing ulur mencapai 6,86 ton per bulan.

Berdasarkan data bulanan periode 2001-2005, rata-rata produksi aktual sebesar 16,750 ton per bulan. Rata-rata total produksi aktual tertinggi terjadi pada bulan Mei 2004 yaitu sebesar 35,56 sedangkan total produksi aktual terendah terjadi pada bulan Januari dan September 2001 yaitu sebesar 8,87 ton. Perkembangan produksi aktual ikan tenggiri per bulan selama tahun 2001-2005 digambarkan pada Gambar 3.

Total effort dari masing-masing alat tangkap untuk penangkapan ikan tenggiri pada perairan Kabupaten Bangka bulanan pada tahun 2001-2005 cenderung berfluktuatif dengan effort rata-rata sebanyak 798 trip per bulan.

Effort tertinggi dicapai pada bulan Desember 2001, yaitu sebanyak 2.586 trip dan terendah terjadi pada Juli 2001 sebanyak 114 trip. Berdasarkan alat tangkap yang dominan, rata-rata effort dari alat tangkap gillnet lebih besar, yaitu 636 trip per bulan dibandingkan dengan ratarata effort dari alat tangkap pancing sebesar 301 trip per bulan (Gambar 4).

\subsection{Standarisasi effort}

Standarisasi upaya yang dilakukan pada penangkapan target species dengan alat tangkap dominan dilakukan dalam rangka estimasi parameter biologi dalam perikanan yang multi species dan multi gear untuk menghindari variasi species (ikan yang tertangkap dalam upaya yang 
dilakukan selain target species) dan variasi gear (alat tangkap yang ada dari alat tangkap sejenis yang tidak beroperasi).

Standarisasi effort dilakukan dengan menggunakan unit jumlah trip per bulan selama tahun 2001-2005 dari dua alat tangkap, yaitu pancing dan gillnet yang distandarisasikan ke alat tangkap pancing dengan standar effort rata-rata sebesar 798 trip artinya jumlah effort standar yang dilakukan selama per bulan dalam usaha penangkapan ikan tenggiri oleh nelayan yaitu sebesar 798 trip.

Penentuan kedua alat tangkap gillnet dan pancing didasarkan pada kondisi bahwa kedua alat tangkap ini merupakan alat tangkap yang dominan digunakan untuk menangkap ikan tenggiri di lokasi penelitian. Kedua alat tangkap tersebut memiliki kemampuan tangkap yang berbeda dalam menangkap ikan tenggiri, maka diperlukan standarisasi unit fishing effort. Pancing dijadikan alat tangkap standard, mengingat rasio rata-rata CPUE dari alat tangkap pancing sebesar 0,03 lebih besar dibandingkan alat tangkap gillnet yaitu sebesar 0,02.

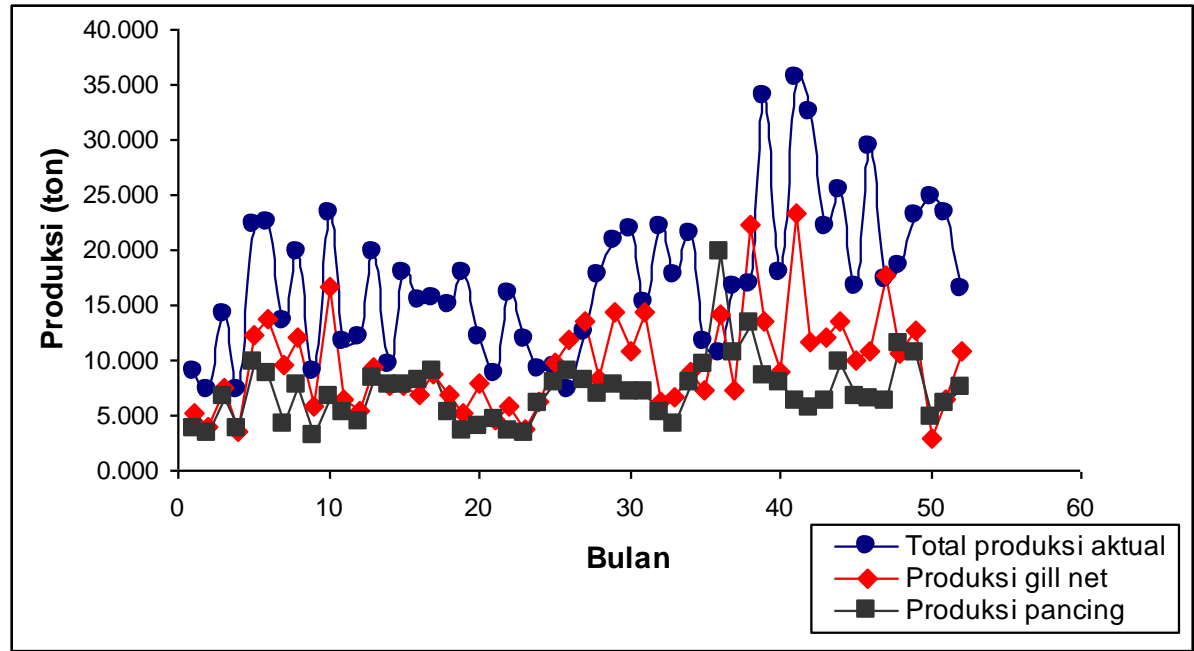

Gambar 3 Perkembangan produksi aktual ikan tenggiri bulanan (2001-2005)

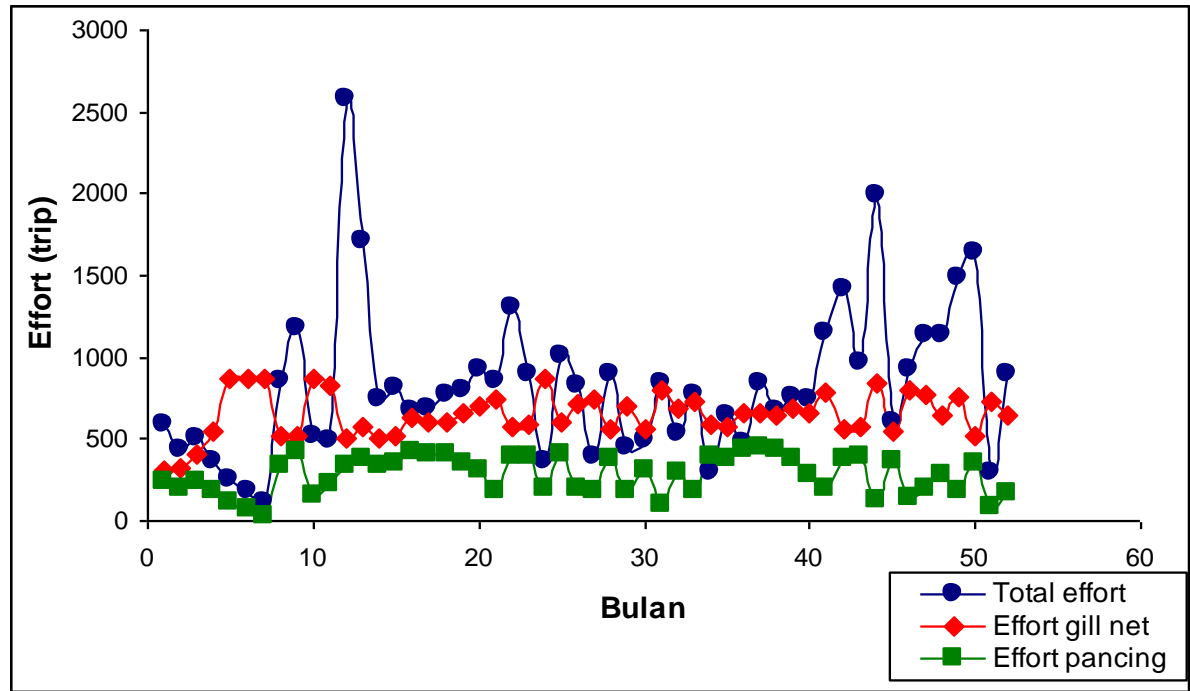

Gambar 4 Perkembangan effort ikan tenggiri bulanan (2001-2005)

\subsection{Hubungan CPUE dan effort}

Produksi bulanan sumberdaya ikan tenggiri dengan alat tangkap gillnet dan pancing di Kabupaten Bangka khususnya yang didaratkan di PPP Sungailiat tahun
2001-2005 mengalami fluktuasi. Fluktuasi yang terjadi disebabkan karena musim penangkapan yang bervariasi. Nilai CPUE pada alat tangkap gillnet dan pancing juga mengalami fluktuasi dari tahun 2001-2005 
dengan rata-rata sebesar 0,017 dan 0,031 ton per bulan. Nilai tertinggi untuk gillnet pada Juni 2004 sebesar 0,03472840 ton per hari dan untuk pancing pada Mei 2005 terendah CPUE gillnet dan pancing pada Januari 2003 sebesar 0,00996549 dan 0,00925207 ton per bulan.

$$
\text { Hubungan antara upaya }
$$
penangkapan (effort) dengan CPUE (Gambar 5) menunjukkan bahwa peningkatan upaya tangkap akan menyebabkan kenaikan nilai CPUE dengan persamaan regresi $\mathrm{Y}=$ $0,00003 x+0,0554$ yang menunjukkan bahwa jika dilakukan peningkatan upaya penangkapan sebesar satu trip, maka akan mengurangi CPUE sebesar 0,00003 ton per trip. Penurunan CPUE dalam kurun waktu bulanan pada tahun 2001-2005 karena terjadinya peningkatan jumlah unit penangkapan ikan tenggiri, tidak diikuti dengan peningkatan produksi. Berdasarkan persamaan tersebut diperoleh nilai $\mathrm{a}=$ 0,0554 dan $b=-0,00003$. Berdasarkan nilai parameter a dan b, maka kondisi pemanfaatan sumberdaya ikan tenggiri di Perairan Kabupaten Bangka mengindikasikan telah terjadi overfishing secara biologi (biological overfishing).

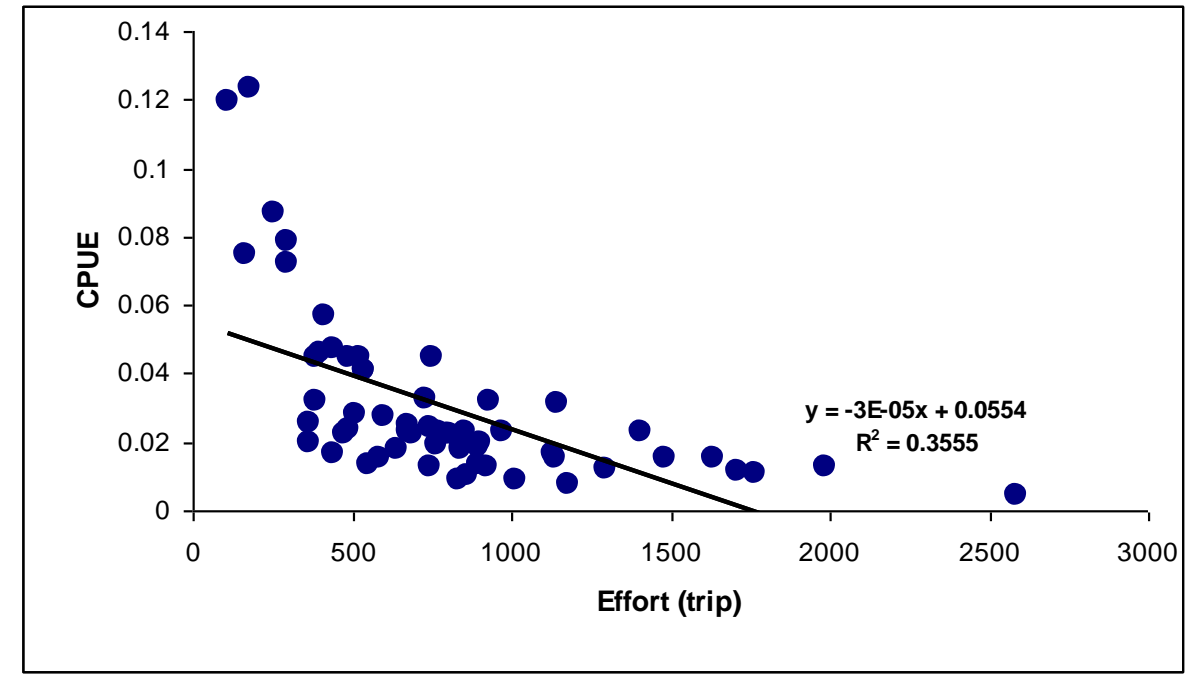

Gambar 5 Hubungan antara CPUE dengan effort bulanan (2001-2005)

Menurut Fauzi (2006), solusi dengan model Schaefer mempunyai kelemahan yaitu parameter biologi $(r, q$ dan $k)$ pada pendekatan CPUE tidak diketahui atau tersembunyi pada parameter regresi $a$ dan $b$ dimana Clark, Yoshimoto dan Pooley mengembangkan model estimator CYP pada tahun 1992 untuk mengetahui parameter biologi. Parameter yang diestimasi berdasarkan model estimator $C Y P$ yang meliputi tingkat pertumbuhan intrinsik $(r)$, koefisien daya tangkap $(q)$ dan daya dukung lingkungan $(k)$. Estimasi parameter bioteknik dapat dilihat pada Tabel 3.
Hasil ketiga parameter biologi tersebut sangat berguna dalam menentukan tingkat produksi lestari (MSY). Berdasarkan nilai parameter biologi yang diperoleh dari model CYP (Tabel 3), maka dapat dihitung nilai produksi lestari. Produksi lestari merupakan hubungan antara hasil tangkapan dengan effort dalam bentuk kuadratik, dimana tingkat effort maupun hasil tangkapan yang diperoleh tidak akan mengancam kelestarian sumberdaya perikanan. Produksi aktual merupakan hasil tangkapan nelayan yang dicatat secara resmi dalam statistik perikanan.

Tabel 3 Hasil estimasi parameter bio-teknik dengan model CYP

\begin{tabular}{|l|r|}
\hline \multicolumn{1}{|c|}{ Parameter } & Nilai \\
\hline$r$ (ton per bulan) & 2,332 \\
\hline$q$ (ton per trip) & 0,002 \\
\hline$k$ (ton per bulan) & 22,931 \\
\hline
\end{tabular}

Sumber : Hasil analisis 2007

Apabila eksploitasi dilakukan terus menerus tanpa memikirkan aspek keles- tarian stok sumberdaya beserta lingkungan perairannya berakibat semakin sedikitnya 
sumberdaya tersebut. Jika dengan memberi kesempatan setiap ikan tenggiri melakukan tingkah laku reproduksi minimal satu kali, maka jumlah populasi akan dapat dipertahankan. Hubungan antara produksi aktual dan produksi lestari dengan upaya pemanfaatan ikan tenggiri di Kabupaten Bangka dapat dilihat pada Gambar 6.

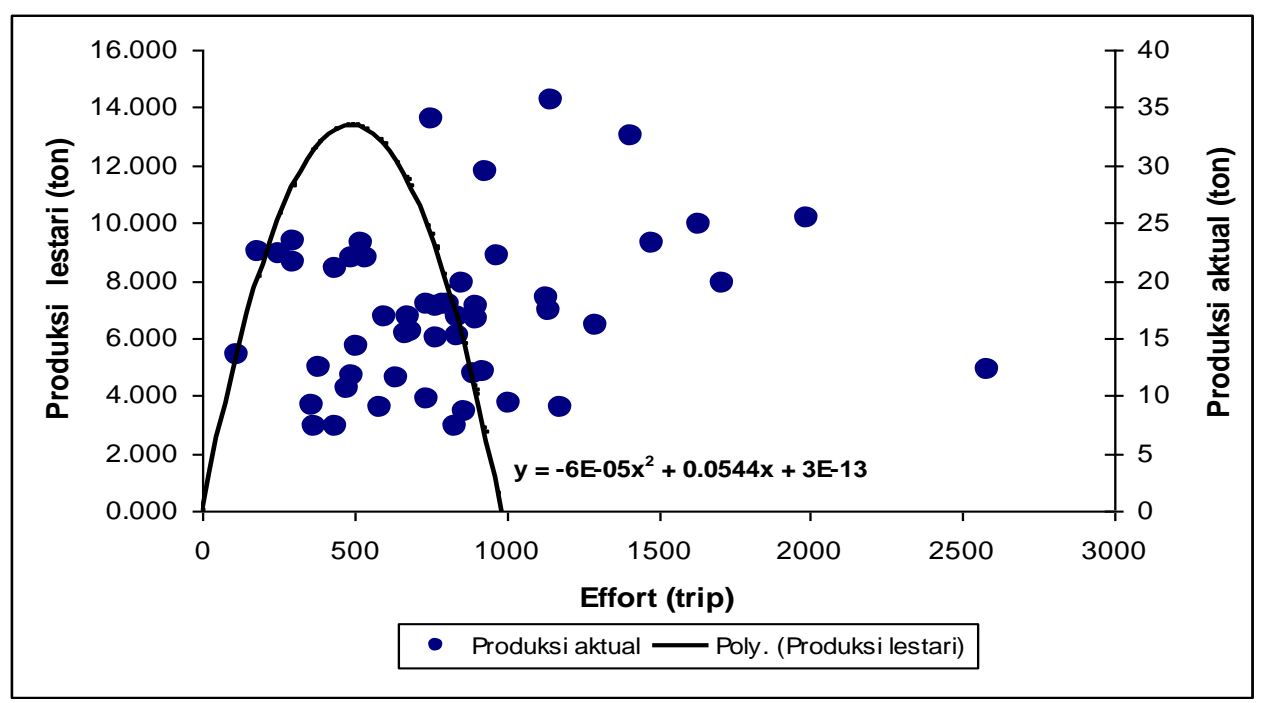

Gambar 6 Hubungan antara produksi aktual dan produksi lestari pada upaya pemanfaatan ikan tenggiri

Gambar 6 menunjukkan semakin tinggi effort justru menyebabkan sebagian besar produksi aktual berada di atas produksi lestari, hal ini menunjukkan bahwa penangkapan ikan di Perairan Kabupaten Bangka telah terjadi biological overfishing. Rata-rata effort aktual yang digunakan selama 5 (lima) tahun sebesar 798 trip per bulan. Meningkatnya effort menyebabkan produksi aktual sebagian besar berada di atas produksi lestari.

Kondisi MSY merupakan batas dari pemanfaatan sumberdaya ikan tenggiri yang dapat dilakukan tanpa mengganggu kelestariannya untuk tumbuh kembali. Pada kondisi ini merupakan kondisi maksimum lestari, yang apabila hasil tangkapan aktual lebih besar dari pada kondisi ini akan menyebabkan hasil tangkapan ikan tenggiri menjadi tidak sustainable. Kondisi biomassa sumberdaya ikan tenggiri pada kondisi MSY sebesar 11,47 ton per bulan, produksi sebesar 13,37 ton per bulan, dan upaya sebesar 491 trip per bulan. Dari hasil perhitungan maka jumlah unit alat tangkap optimal setara dengan pacing ulur sebanyak 167-168 unit.

Pada kondisi aktual hasil tangkapan ikan tenggiri yang diperoleh, yaitu sebesar 17,41 ton per bulan. Apabila dilihat dari besarnya tingkat upaya yang dilakukan, dapat terlihat bahwa pada kondisi $M S Y$ upaya yang dilakukan lebih kecil dibandingkan pada kondisi aktual, yaitu sebesar 798 trip per bulan. Berdasarkan kondisi pemanfaatan sumberdaya ikan tenggiri tersebut di Perairan Kabupaten Bangka, maka telah terjadi overfishing secara biologi (biological overfishing) (Tabel 4).

Tabel 4 Pola Pemanfaan sumberdaya ikan tenggiri model statistik

\begin{tabular}{|c|l|r|r|}
\hline No. & \multicolumn{1}{|c|}{ Parameter } & \multicolumn{1}{|c|}{ MSY } & \multicolumn{1}{c|}{ Aktual } \\
\hline 1. & $\mathrm{x}$ (ton) & 11,47 & 17,41 \\
\hline 2. & $\mathrm{~h}$ (ton) & 13,37 & 798 \\
\hline 3. & $\mathrm{E}$ (trip) & 491 & \\
\hline
\end{tabular}

Sumber : Hasil analisis 2007

Berdasarkan analisis degradasi sumberdaya perikanan tenggiri, maka wilayah perairan di Kabupaten Bangka selama 2001-2005 belum terdegradasi, karena rata-rata laju degradasi masih di bawah nilai standar, yaitu laju degradasi rata-rata sebesar 0,44 per bulan. Hal ini berarti belum terjadi penurunan kualitas dan kuantitas sumberdaya ikan tenggiri. Laju degradasi yang terjadi selama tahun 
2001-2005 cenderung meningkat dengan mengikuti persamaan $\mathrm{y}=0,0023 \mathrm{x}+0,3701$. Kecenderungan meningkatnya laju degradasi sumberdaya ikan tenggiri di Kabupaten Bangka erat kaitannya dengan tingkat ekploitasi sumberdaya ikan tenggiri yang semakin besar (Gambar 7).

\subsection{Distribusi Pemasaran Ikan Tenggiri Saluran pemasaran}

Pemasaran hasil tangkapan usaha perikanan tenggiri di Kabupaten Bangka baik pasar ikan lokal untuk kebutuhan masyarakat maupun perusahaan untuk tujuan pasar ekspor dilakukan dalam 4 (empat) saluran, yaitu :

1) Dipasarkan secara langsung ke perusahaan perikanan dengan harga jual yang telah ditentukan bersama kemudian didistribusikan untuk pasar eksportir.

2) Dipasarkan secara langsung ke pedagang pengumpul untuk selanjutnya dipasarkan langsung ke perusahaan perikanan selanjutnya untuk pasar eksportir.

3) Dipasarkan secara langsung ke pedagang pengumpul kemudian dipasarkan kembali ke pedagang pengecer dan didistribusikan ke konsumen pasar lokal yang berada di dalam maupun luar Kabupaten Bangka.

4) Dipasarkan secara langsung ke pedagang pengecer untuk selanjutnya dipasarkan langsung ke konsumen lokal baik yang berada di Kabupaten Bangka maupun di luar Kabupaten Bangka (Gambar 8).

\subsection{Margin pemasaran}

Hasil wawancara dengan responden pada saluran pemasaran I menunjukkan bahwa perusahaan perikanan mengeluarkan biaya penanganan komoditas hingga berada di kapal tujuan ekspor sebesar Rp1.435,00 per kg, biaya yang dikeluarkan oleh pedagang pengumpul dalam penanganan hasil tangkapan sebesar $\mathrm{Rp} 365,00$ per $\mathrm{kg}$ dan penanganan hasil tangkapan oleh pedagang pengecer $\mathrm{Rp}$ 316,00 per kg. Biaya-biaya yang dikeluarkan oleh pedagang pengumpul meliputi penggunaan es dan trasportasi guna pengangkutan ikan dari dermaga hingga ke perusahaan perikanan.

Biaya-biaya yang dikeluarkan oleh pedagang pengecer untuk penanganan hasil perikanan meliputi penggunaan es, transportasi yang digunakan untuk pengangkutan ikan ke pasar dan sewa tempat dimana pedagang pengecer menjualkan ikan-ikannya, sedangkan untuk perusahaan perikanan biaya yang dikeluarkan lebih banyak seperti biaya penggunaan es, transportasi yang digunakan untuk pengangkutan ikan hingga ke konteiner, biaya sortir dan pengepakan serta biaya penanganan dari kontainer sampai masuk ke kapal tujuan ekspor/antar pulau (Tabel 5).

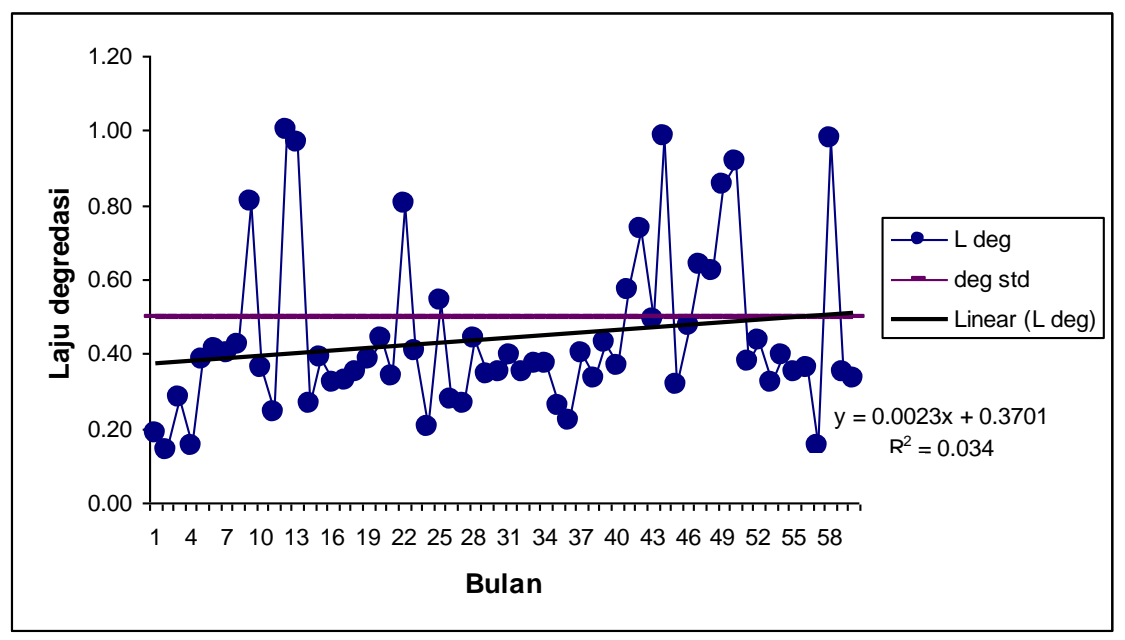

Gambar 7 Laju degradasi sumberdaya ikan tenggiri 


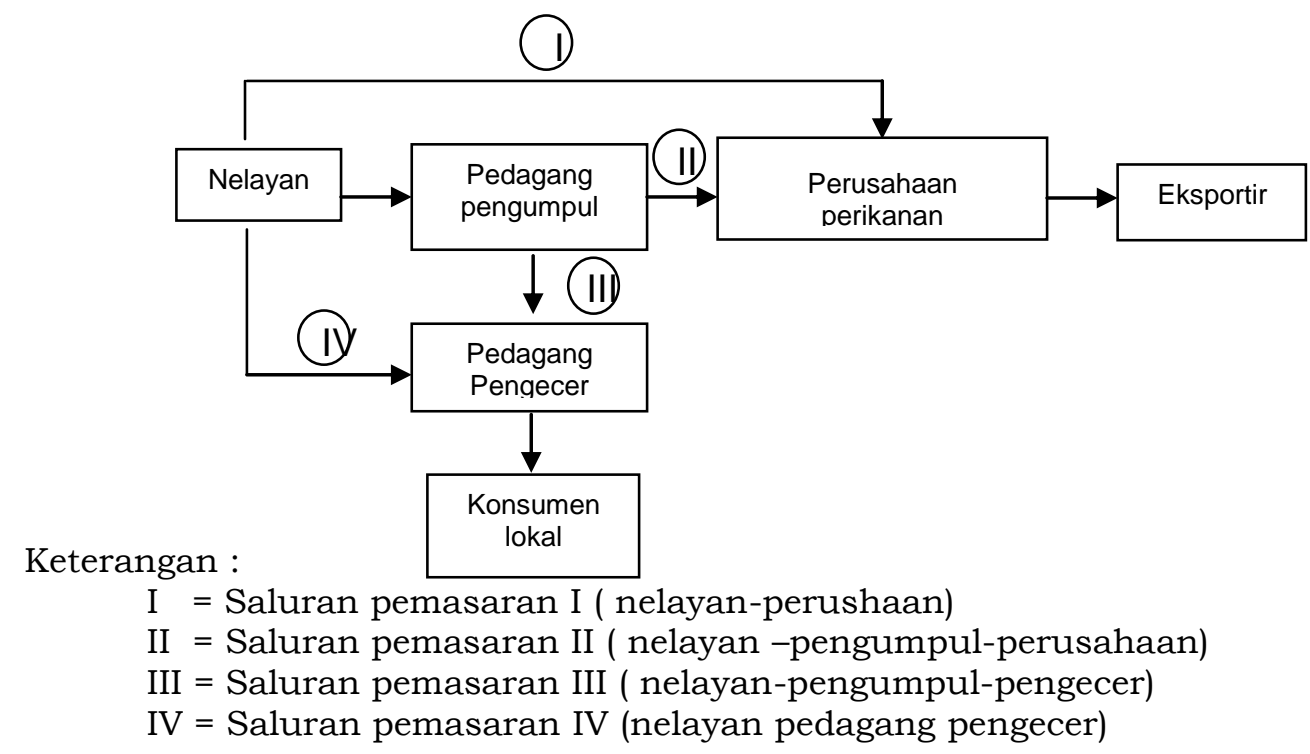

Gambar 8 Skema saluran pemasaran hasil tangkapan ikan tenggiri di Kabupaten Bangka

\subsection{Margin pemasaran}

Hasil wawancara dengan responden pada saluran pemasaran I menunjukkan bahwa perusahaan perikanan mengeluarkan biaya penanganan komoditas hingga berada di kapal tujuan ekspor sebesar Rp1.435,00 per kg, biaya yang dikeluarkan oleh pedagang pengumpul dalam penanganan hasil tangkapan sebesar $\mathrm{Rp} 365,00$ per $\mathrm{kg}$ dan penanganan hasil tangkapan oleh pedagang pengecer $\mathrm{Rp}$ 316,00 per kg. Biaya-biaya yang dikeluarkan oleh pedagang pengumpul meliputi penggunaan es dan trasportasi guna pengangkutan ikan dari dermaga hingga ke perusahaan perikanan.
Biaya-biaya yang dikeluarkan oleh pedagang pengecer untuk penanganan hasil perikanan meliputi penggunaan es, transportasi yang digunakan untuk pengangkutan ikan ke pasar dan sewa tempat dimana pedagang pengecer menjualkan ikan-ikannya, sedangkan untuk perusahaan perikanan biaya yang dikeluarkan lebih banyak seperti biaya penggunaan es, transportasi yang digunakan untuk pengangkutan ikan hingga ke konteiner, biaya sortir dan pengepakan serta biaya penanganan dari kontainer sampai masuk ke kapal tujuan ekspor/antar pulau (Tabel 5).

Tabel 5 Biaya penanganan hasil tangkapan ikan tenggiri

\begin{tabular}{llr}
\hline No & \multicolumn{1}{c}{ Keterangan } & Biaya (Rp per kg) \\
\hline & Pedagang pengumpul (1.900 kg) & 215 \\
1 & Penggunaan es & 150 \\
2 & Transportasi dari dermaga ke perusahaan perikanan & 365 \\
\hline & Total & 135 \\
& Pedagang pengecer (200 $\mathbf{~ k g ) ~}$ & 125 \\
1 & Penggunaan es harian & 56 \\
2 & Transportasi ke pasar & 316 \\
3 & Sewa tempat & 100 \\
& Total & 55 \\
& Perusahaan perikanan (4.200 kg) & 30 \\
1 & Penggunaan es & 1.250 \\
2 & Transportasi dari perusahaan perikanan ke kontainer & 1.435 \\
3 & Biaya sortir dan pengepakan \\
4 & Penanganan dari kontainer ke kapal tujuan ekspor & \\
\hline & Total
\end{tabular}


Harga jual ikan tenggiri oleh perusahaan maupun harga lokal yang dijual oleh nelayan kepada pedagang pengumpul, maka terdapat perbedaan yang cukup signifikan. Besar margin keuntungan yang diperoleh perusahaan perikanan akan tereduksi jika pembelian dilakukan melalui pedagang pengumpul (saluran pemasaran II). Hal ini disebabkan porsi margin harus dibagi dengan pedagang pengumpul. Ratarata margin pemasaran yang dinikmati pedagang pengumpul yaitu sebesar $R p$ $2.500,00$ per $\mathrm{kg}$ dan pada perusahaan perikanan pada saluran pemasaran I dan II yaitu sebesar Rp 6.700,00 per kg dan Rp 9.200,00. Perbedaan harga jual dan margin pemasaran pada saluran distribusi komoditas ikan tenggiri dapat dilihat pada Tabel 6.

Pada setiap ikan per kilogram dikena- kan biaya pemasaran oleh pedagang pengumpul sebesar Rp 365,00 per kg dengan share $0,94 \%$ dan perusahaan perikanan sebesar $\mathrm{Rp} 1.435,00$ per $\mathrm{kg}$ dengan share $3,71 \%$. Besarnya harga penjualan yang diperoleh nelayan dari hasil penjualan ke pedagang pengumpul dan perusahaan perikanan yaitu sebesar $\mathrm{Rp}$ $29.450,00$ dengan share $76,20 \%$. Jika dilihat dari keuntungan pedagang pengumpul memperoleh keuntungan sebesar Rp 2.135,00 per kg dengan share $5,52 \%$ dan perusahaan perikanan sebesar Rp 5.265,00 per kg dengan share $13,62 \%$ pada saluran pemasaran I.

Pada saluran pemasaran II biaya yang dikeluarkan oleh perusahaan dapat mengalami keuntungan sebesar Rp $7.765,00$ per $\mathrm{kg}$ dengan share sebesar $20,09 \%$.

Tabel 6 Margin pemasaran, biaya pemasaran dan keuntungan pemasaran pada saluran I dan II

\begin{tabular}{|l|l|r|r|r|r|}
\hline \multirow{2}{*}{ No. Uraian } & \multicolumn{1}{|c|}{ Saluran pemasaran I } & \multicolumn{2}{c|}{ Saluran pemasan II } \\
\cline { 3 - 6 } & & Rp per kg & \multicolumn{1}{c|}{ Share (\%) } & \multicolumn{1}{c|}{ Rp per kg } & Share (\%) \\
\hline I. & Nelayan & & & & \\
\hline & a. Harga jual & 29.450 & 76,20 & 29.450 & 76,20 \\
\hline 2. & Pedagang pengumpul & & & & - \\
\hline & a. Harga jual (Rp per kg) & 31.950 & 82,66 & - & - \\
\hline & b. Harga pokok (Rp per kg) & 29.450 & 76,20 & & - \\
\hline & c. Margin pemasaran (Rp per kg) & 2.500 & 6,47 & & - \\
\hline & d. Biaya pemasaran (Rp per kg) & 365 & 0,94 & & - \\
\hline & $\begin{array}{l}\text { e. Keuntungan pemasaran (Rp per } \\
\text { kg) }\end{array}$ & 2.135 & 5,52 & & \\
\hline 3. & Perusahaan perikanan & & & & - \\
\hline & a. Harga jual (Rp per kg) & 38.650 & 100,00 & 38.650 & 100,00 \\
\hline & b. Harga pokok (Rp per kg) & 31.950 & 82,66 & 29.450 & 76.20 \\
\hline & c. Margin pemasaran (Rp per kg) & 6.700 & 17,34 & 9.200 & 23,80 \\
\hline & d. Biaya pemasaran (Rp per kg) & 1.435 & 3,71 & 1.435 & 3,71 \\
\hline & $\begin{array}{l}\text { e. Keuntungan pemasaran (Rp per } \\
\text { kg) }\end{array}$ & 5.265 & 13,62 & 7.765 & 20,09 \\
\hline
\end{tabular}

Sumber : Data diolah dari data primer, 2007

Rata-rata margin pemasaran yang dinikmati pedagang pengumpul pada saluran pemasaran III dan IV yaitu sebesar Rp $1.800,00$ per kg dengan share $5,20 \%$ dan pedagang pengecer pada saluran pemasaran III dan IV yaitu sebesar Rp 7.500,00 per kg dengan share $21,68 \%$.

Setiap ikan per kilogram biaya penanganan yang dikeluarkan oleh pedagang pengumpul sebesar Rp 316,00 per $\mathrm{kg}$ dengan share $0,91 \%$ dan pedagang pengecer sebesar Rp 365,00 per kg dengan share $1,05 \%$. Jika dilihat dari keuntungan pemasaran pedagang pengumpul memperoleh keuntungan sebesar Rp $1.484,00$ per $\mathrm{kg}$ dengan share $4,29 \%$ dan pedagang pengecer sebesar Rp 7.135,00 per $\mathrm{kg}$ dengan share $20,62 \%$. Share nelayan (fishermen share) yang diperoleh pada saluran pemasaran III dan IV sebesar $73,12 \%$, artinya bagian yang diterima oleh nelayan pada saluran III dan IV adalah sebesar 73,12\% (Tabel 7). Keuntungan yang diperoleh dengan saluran makin pendek dengan fisherman share yang sama akan memberikan share bagi pedagang lebih besar. 
Tabel 7 Margin pemasaran, biaya pemasaran dan keuntungan pemasaran pada saluran III dan IV

\begin{tabular}{|c|c|c|c|c|c|}
\hline \multirow[b]{2}{*}{ No } & \multirow{2}{*}{ Uraian } & \multicolumn{2}{|c|}{$\begin{array}{c}\text { Saluran } \\
\text { pemasaran III }\end{array}$} & \multicolumn{2}{|c|}{$\begin{array}{c}\text { Saluran } \\
\text { pemasaran IV }\end{array}$} \\
\hline & & $\begin{array}{c}\text { Rp per } \\
\text { kg }\end{array}$ & $\begin{array}{c}\text { Share } \\
(\%)\end{array}$ & $\begin{array}{c}\text { Rp per } \\
\text { kg }\end{array}$ & $\begin{array}{c}\text { Share } \\
(\%)\end{array}$ \\
\hline \multirow[t]{2}{*}{1.} & Nelayan & & & & \\
\hline & a. Harga jual & 25.300 & 73,12 & 25.300 & 73,12 \\
\hline \multirow[t]{6}{*}{2.} & Pedagang pengumpul & & & & \\
\hline & a. Harga jual (Rp per kg) & 27.100 & 78,32 & - & - \\
\hline & b. Harga pokok (Rp per kg) & 25.300 & 73,12 & - & - \\
\hline & c. Margin pemasaran (Rp per kg) & 1.800 & 5,20 & - & - \\
\hline & d. Biaya pemasaran (Rp per kg) & 316 & 0,91 & - & - \\
\hline & $\begin{array}{l}\text { e. Keuntungan pemasaran (Rp per } \\
\mathrm{kg} \text { ) }\end{array}$ & 1.484 & 4,29 & - & \\
\hline \multirow[t]{6}{*}{3.} & Pedagang pengecer & & & & \\
\hline & a. Harga jual (Rp per kg) & 34.600 & 100,00 & 34.600 & 100,00 \\
\hline & b. Harga pokok (Rp per kg) & 27.100 & 78,32 & 25.300 & 73,12 \\
\hline & c. Margin pemasaran (Rp per kg) & 7.500 & 21,68 & 9.300 & 26,88 \\
\hline & d. Biaya pemasaran (Rp per kg) & 365 & 1,05 & 365 & 1,05 \\
\hline & $\begin{array}{l}\text { e. Keuntungan pemasaran (Rp per } \\
\mathrm{kg} \text { ) }\end{array}$ & 7.135 & 20,62 & 8.835 & 25,53 \\
\hline
\end{tabular}

Sumber : Data diolah dari data primer, 2007

\section{KESIMPULAN}

1) Ikan tenggiri di perairan Kabupaten Bangka ditangkap dengan menggunakan alat tangkap gillnet dan pacing ulur. Jaring insang di Kabupaten Bangka termasuk dalam jaringi insang hanyut (drift gillnet) dan nelayan menyebut jaring ini dengan istilah jaring tenggiri. Kontruksi alat tangkap ini terdiri atas tali selambar, jaring, pelampung dan tali ris atas. Pancing ulur untuk penangkapan ikan tenggiri memiliki konstruksi yang terdiri atas reel (rooler), kili-kili (swivel), senar (line), pemberat (sinker) dan mata pancing (hook). Musim penangkapan ikan yang ada di Perairan Bangka pada bulan-bulan dimana terjadi musim ikan yaitu pada Bulan Maret, Mei dan Juni serta Agustus dan Oktober dengan IMP lebih dari $100 \%$. Daerah penangkapan pemanfaatan fishing ground ikan tenggiri di Perairan Kabupaten Bangka, yaitu pada jalur penangkapan 1 (pada perairan dari pantai sampai 6 mil).

2) Produksi aktual rata-rata pada usaha perikanan tenggiri di Kabupaten Bangka yaitu sebesar 17,41 ton, sedangkan pada kondisi MSY yaitu sebesar 13,37 ton. Effort aktual rata-rata pada usaha perikanan tenggiri di Kabupaten Bangka, yaitu sebesar 798 trip per bulan, sedangkan pada kondisi MSY sebesar
491 trip. Berdasarkan kondisi pemanfaatan sumberdaya ikan tenggiri tersebut di Perairan Kabupaten Bangka, maka diduga telah terjadi overfishing secara biologi (biological overfishing) Jumlah unit alat tangkap yang optimal sebanyak 167-168 unit.

3) Pemasaran lokal ikan tenggiri dilakukan oleh pedagang pengumpul dan pedagang pengecer dan selanjutnya dijual ke konsumen, sedangkan pemasaran ekspor dilakukan oleh perusahaan. Harga jual, margin pemasaran dan keuntungan yang diperoleh dengan saluran makin pendek dengan fisherman share yang sama akan memberikan share bagi pedagang dan perusahaan perikanan lebih besar.

\section{DAFTAR PUSTAKA}

Clark CW. 1985. Bioeconomic Modelling and Fisheries Management. Departement of Mathematics Univesity of British Columbia. A Willey-Interscience Publication John Wiley and sons. New York.300 p.

Dinas Kelautan dan Perikanan Kabupaten Bangka. 2006. Data Perikanan Kabupaten Bangka 2005. Sungailiat : DKP Kabupaten Bangka. 118 hlm. 
Fauzi A. 2006. Ekonomi Sumberdaya Alam dan Lingkungan. Jakarta : PT Gramedia Pustaka Utama. 259 hlm.

Schaefer MB. 1954. Some Consideration of Population Dynamic and Economic in Relation to the Manegement of the Commercial Marine Fisheries. Bull. Inter-Am. Trop. Tuna. Comm 1:27-56.
Sobari MP, Diniah, Widiastuti. 2007. Kajian Model Bionomi terhadap Pengelolaan Sumberdaya Ikan Layur di Perairan Palabuhanratu. [makalah seminar] Seminar Nasional Perikanan Tangkap. Desember 2007. Bogor: Departemen Pemanfaatan Sumberdaya Perikanan. 